\title{
Sex differences in behavioral impulsivity in at-risk and non-risk drinkers
}

\author{
Jessica Weafer, Jessica De Arcangelis and Harriet de Wit* \\ Department of Psychiatry and Behavioral Neuroscience, University of Chicago, Chicago, IL, USA
}

Introduction: Mounting evidence from both animal and human studies suggests that females are more vulnerable to drug and alcohol abuse than males. Some of this increased risk may be related to behavioral traits, such as impulsivity. Here, we examined sex differences in two forms of behavioral impulsivity (inhibitory control and impulsive choice) in young men and women, in relation to their level of alcohol consumption and alcohol-related problems (at-risk or non-risk).

Methods: Participants performed a go/no-go task to assess inhibitory control and a measure of delay discounting to assess impulsive choice.

\section{OPEN ACCESS}

Edited by:

Liana Fattore,

National Research Council, Italy

Reviewed by:

Giovanni Martinotti,

University G. d'Annunzio, Italy

Kesong $\mathrm{Hu}$,

Cornell University, USA

*Correspondence:

Harriet de Wit,

Department of Psychiatry and

Behavioral Neuroscience, University of Chicago, 5841 South Maryland

Avenue, Chicago, IL 60637, USA

hdew@uchicago.edu

Specialty section:

This article was submitted to Addictive Disorders and Behavioral Dyscontrol, a section of the journal Frontiers in Psychiatry

Received: 21 March 2015 Accepted: 29 April 2015

Published: 13 May 2015

Citation:

Weafer J, De Arcangelis J and de Wit $H$ (2015) Sex differences in behavioral impulsivity in at-risk and non-risk drinkers. Front. Psychiatry 6:72. doi: 10.3389/fpsyt.2015.00072
Results: On the measure of inhibitory control, at-risk women committed significantly more inhibitory errors than at-risk men, indicating poorer behavioral control among the women. By contrast, no sex differences were observed between at-risk men and women in delay discounting, or between the male and female non-risk drinkers on any measure.

Conclusion: Heavy drinking women displayed poorer inhibitory control than heavy drinking men. It remains to be determined whether the sex differences in inhibitory control are the result of drinking, or whether they pre-dated the problematic drinking in these individuals.

Keywords: behavioral impulsivity, inhibitory control, impulsive choice, go/no-go, delay discounting, alcohol, AUDIT

\section{Introduction}

Alcohol abuse has been traditionally considered a male-oriented problem and as a consequence research on risk factors specific to women has been minimal. However, the sex gap in alcohol consumption and alcohol-related problems is closing rapidly, especially among young adult drinkers (1-4). Specifically, sex differences in frequency and quantity of alcohol consumption, frequency of binge drinking, and prevalence of alcohol abuse and dependence are shrinking, due primarily to increased consumption and prevalence rates in women. In fact, binge drinking rates in women are beginning to surpass those in men in some areas (5). Further, findings from both animal and human studies suggest that females may actually be more vulnerable to drug and alcohol use than males (6-8). Given the increase in alcohol use among women and their increased vulnerability to alcohol-related problems, it is important to identify risk factors for alcohol abuse in women.

One potential risk factor is impulsive behavior. Growing evidence indicates that there are at least two separate components of impulsive behavior: poor inhibitory control (behavioral disinhibition) and impulsive choice (delay discounting), and both forms are strongly implicated in alcohol and drug abuse (9-11). Alcohol-dependent individuals display poor inhibitory control compared to 
healthy, social drinking controls $(12,13)$, and poor inhibitory control prospectively predicts the development of alcohol-related problems (14-16). Heavy drinkers also display greater impulsive choice (i.e., steeper discounting of the value of rewards that are delivered after a delay) than social drinking controls (17, 18 ), and delay discounting prospectively predicts greater alcohol consumption among adolescents over a 2-year period (16).

There is some evidence that healthy men and women differ on measures of impulsive behaviors, although results are mixed and depend on specific tasks administered (19). Regarding inhibitory control, women and girls exhibit poorer inhibition than males on stop signal tasks, which measure the time required to inhibit a response $(20,21)$. By contrast, men exhibit poorer inhibition on go/no-go tasks, which measure the number of inhibitory failures (22-24). Regarding delay discounting, some studies have found that women discount more than men using hypothetical or chance (based on the role of the die) discounting procedures (25-27), whereas other studies have found greater discounting in men using both hypothetical and chance (based on a lottery) discounting procedures $(28,29)$. Taken together, sex differences do appear to exist, but the direction of the differences varies across specific domains of impulsive behavior.

To date, only a handful of studies have examined sex differences in impulsive behaviors among problematic drinkers. The interpretation of studies with experienced users is complex, as it is difficult to determine whether any observed behavioral differences pre-dated and contributed to the drinking, or whether the behaviors changed as a result of the drinking. Nevertheless, the findings are informative and useful in designing interventions. Initial evidence shows that heavy, binge drinking women display greater inhibitory deficits compared to both heavy drinking men and light drinkers, on both stop signal and go/no-go tasks (30, 31). By contrast, Bobova et al. (32) found that heavy drinking men discounted a hypothetical monetary reward more than heavy drinking women, although this sex difference was not specific to heavy drinkers. Finally, Yankelevitz et al. (33) examined sex differences in discounting of hypothetical money and hypothetical alcohol in regular drinkers. Although men and women did not differ for either commodity alone, women discounted alcohol more than money, whereas men discounted the two commodities equally. In sum, evidence suggests that poor inhibitory control could be a specific risk factor for heavy, problematic drinking in women, but the current findings regarding sex differences in impulsive choice among drinkers are equivocal.

The current study examined sex differences in both inhibitory control and impulsive choice as a function of drinking status in a community sample of young adult drinkers $(n=743)$. Participants were classified as "at-risk" or "non-risk" drinkers based on their scores on the Alcohol Use Disorders Identification Test [AUDIT; (34)]. The AUDIT is a screening instrument that classifies individuals based on both patterns of alcohol consumption (i.e., frequency and quantity) as well as occurrence of negative alcoholrelated consequences. Participants who met the cutoff score of 8 or higher for hazardous drinking were classified as at-risk and those who scored below 8 were considered to be non-risk. Participants performed the go/no-go task to assess inhibitory control and the delay discounting task (DDT) to assess impulsive choice.
We hypothesized that overall, at-risk drinkers would be more impulsive on both tasks (i.e., display greater inhibitory failures and steeper delay discounting) compared to non-risk drinkers. Additionally, we hypothesized that among at-risk drinkers, women would display poorer inhibitory control than men. Analyses of sex differences in delay discounting were considered exploratory, given the lack of consistent findings from previous studies.

\section{Materials and Methods}

\section{Participants}

Volunteers were recruited from the community through online and printed advertisements. Inclusion criteria included ages 18-30, at least a high school education, fluency in English, no current or past year diagnosis (including alcohol or substance dependence) on the Diagnostic and Statistical Manual of Mental Disorders, Fourth Edition (35), no lifetime alcohol or substance dependence (other than caffeine or nicotine), and at least some alcohol consumption within the past year. The study was approved by the Institutional Review Board of the University of Chicago, and was carried out in accordance with the Declaration of Helsinki. Participants provided informed consent and were compensated for their time.

\section{Procedure}

These data were obtained in the course of a larger genetic study. Participants attended a 4-h experimental session (morning or afternoon) during which they completed several behavioral tasks and self-report measures in counterbalanced order. Participants were instructed to abstain from alcohol and drugs (other than their usual amounts of caffeine and nicotine) for $24 \mathrm{~h}$ before the visit, and breath and urine samples were obtained to verify compliance. After compliance testing, participants completed the tasks and questionnaires reported here.

\section{Measures}

\section{Go/No-Go Task}

Inhibitory control was assessed using a go/no-go task (Figure 1) that measures the ability to inhibit inappropriate responses. This task has been used extensively in alcohol and drug abuse research, and findings have consistently found that heavy substance use is associated with greater inhibitory errors $(9,36)$. Go (X) and no-go (K) targets were presented on the computer screen. Participants were told to respond as quickly as possible to go targets but to inhibit their response to the no-go targets. Most (85\%) of the trials were go targets, establishing the "go" response as prepotent, and making it more difficult to inhibit when the no-go targets occasionally appeared. The number of inhibitory failures (i.e., failures to inhibit a response to a no-go target) provided the dependent measure of interest. Data were considered invalid if go target accuracy was less than $55 \%$ or if there were no successful inhibitions (suggesting a lack of understanding of task instructions).

\section{Delay Discounting Task}

Impulsive choice was assessed using a delay discounting task (DDT; Figure 2) that assesses the relative value of immediate 


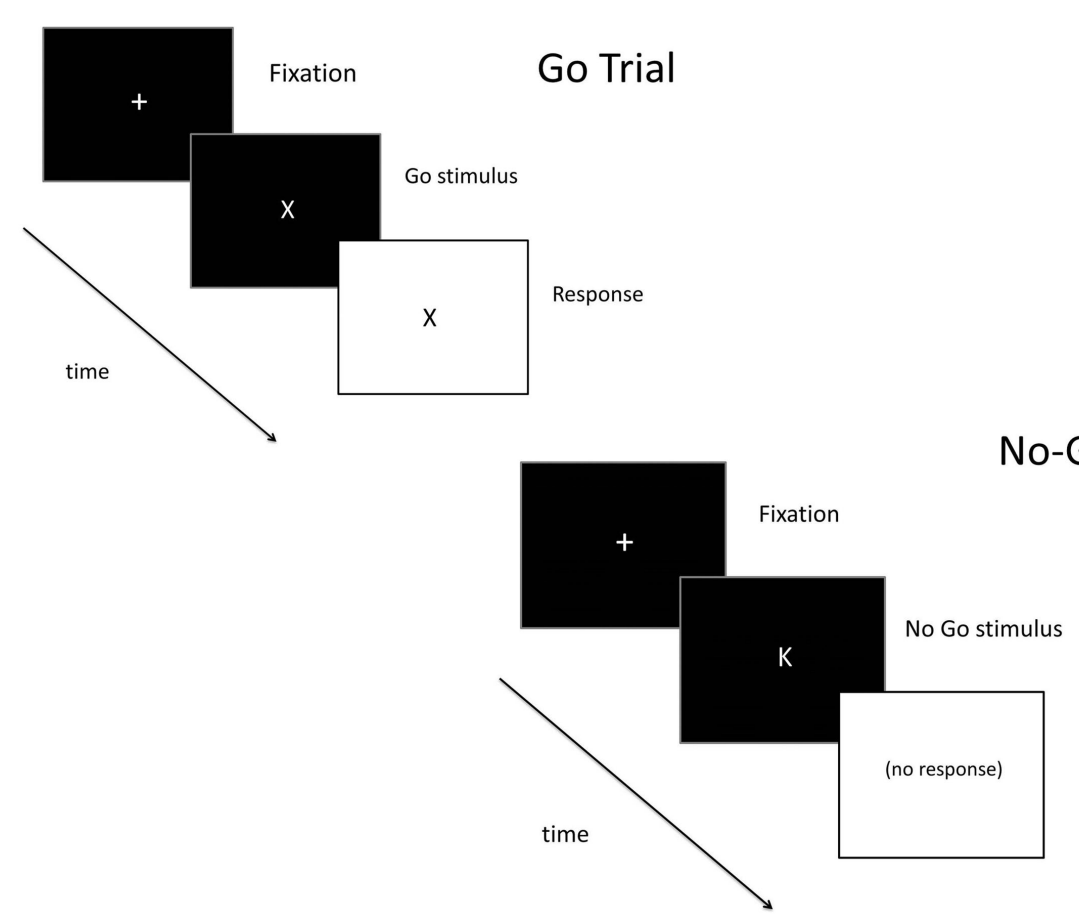

FIGURE 1 | Schematic of a go (top) and no-go (bottom) trial on the go/no-go task.

versus delayed rewards (37). This task has also been used extensively in drug abuse research, and studies have consistently shown greater discounting of delayed rewards by substance abusers ( 9 , $11,17)$. Participants made a series of choices (90 total) between a smaller amount of money (ranging from $\$ 10$ to $\$ 99$ ) delivered immediately, and a larger amount of money $(\$ 100)$ delivered after a delay (i.e., 1, 7, 14, 30, 60, 90, 180, or 365 days). They were told that at the end of the session a random number would be generated and if they guessed the number correctly they would receive the amount of one of their choices. Thus, subjects performed the task knowing that there was a chance they would receive one of their choices. Indifference points were calculated based on the smallest amount of money chosen over the large reward at each delay. Response consistency was calculated at each delay to ensure that participants were performing the task appropriately, and a threshold of $75 \%$ consistency was set to indicate adequate effort. The indifference points were plotted to form a discount function, and the area under the curve (AUC) of the discount function provided the dependent measure of impulsive choice $(27,38)$. A smaller AUC indicates a steeper discounting curve, and therefore greater impulsivity.

\section{Alcohol Use Disorder Identification Test}

The AUDIT is a 10-item self-report measure that assesses patterns of drinking, dependence, and alcohol-related problems. Scores range from 0 (no alcohol-related problems) to 40 (most severe alcohol-related problems), and a score of 8 or greater is typically indicative of hazardous drinking (34). Accordingly, we classified participants with AUDIT scores less than 8 as "non-risk drinkers" and participants with AUDIT scores of 8 or greater as "at-risk drinkers."

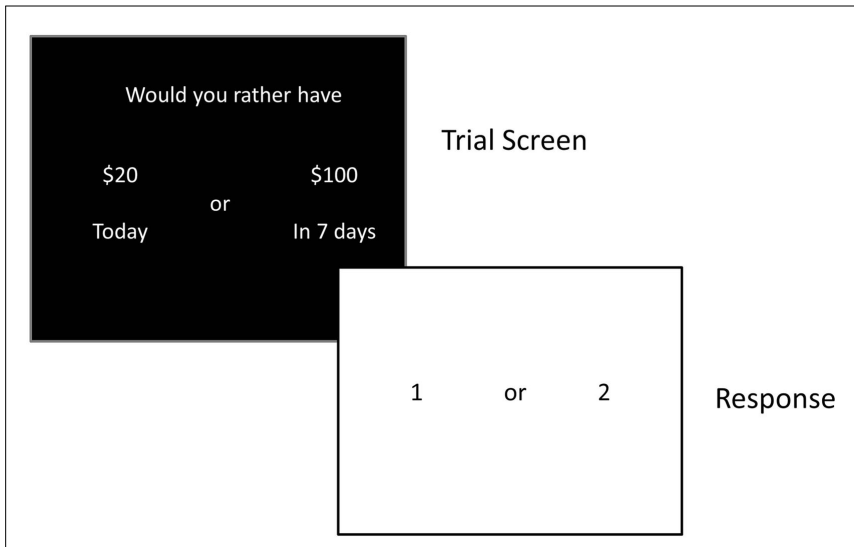

FIGURE 2 | Schematic of a trial on the delay discounting task

\section{Timeline Follow-Back}

Participants completed a retrospective timeline calendar of their alcohol consumption for the past 28 days to assess daily patterns of drinking (39). The measure uses "anchor points" to structure and facilitate participants' recall of past drinking episodes. For each day, participants estimated the number of standard drinks they consumed. The TLFB provided two measures of drinking habits over the past 28 days: (a) drinking days (total number of days alcohol was consumed) and (b) binge days (number of days in which four or more drinks were consumed for women or five or more drinks were consumed for men). The TLFB was added to the study protocol after the study had begun, and thus data from this measure are only available from a subset of participants $(n=457)$. 


\section{Statistical Analysis}

The effects of sex and at-risk drinker status on task performance were analyzed by 2 (sex: male vs. female) $\times 2$ (group: at-risk vs. non-risk) between-groups analyses of variance (ANOVA). Significant interactions were followed by post hoc $t$-tests comparing men and women separately in the at-risk and non-risk groups.

\section{Results}

\section{Sample Characteristics}

The sample consisted of 743 healthy adults (296 men and 447 women; mean age $=22.9$ years, $\mathrm{SD}=3.2$ ). Sample characteristics are presented in Table 1. In the sample as a whole, women were slightly younger than men [between-groups $t$-test: $t(741)=2.5$, $p=0.01]$. No other sex differences in sample demographics were observed (between-groups $t$-tests: $p s>0.64)$. The racial make-up of the sample was as follows: Asian $(n=27)$, African-American $(n=27)$, Caucasian $(n=675)$, and other $(n=14)$. The majority of participants were Caucasian as these data were collected as part of a larger genetic study.

\section{Drinking Habits}

Slightly less than one quarter of the sample $(n=173 ; 90$ men and 83 women) were classified as "at-risk" drinkers (AUDIT scores $\geq 8)$ and the remainder ( $n=570 ; 206$ men and 364 women) were classified as non-risk drinkers (AUDIT scores $<8$ ). There were no risk group differences or sex $\times$ risk group interactions for any demographic variables (Table 1; $p$ s $>0.10$ ). Measures of drinking habits (TLFB and AUDIT) are presented in Table 1 separately for men and women within each group. All alcohol consumption measures were greater in the at-risk compared to the non-risk group (between-groups $t$-tests: $p s<0.001$ ). Men and women in the at-risk drinker group did not differ on any alcohol consumption measures ( $p s>0.05)$. Among the non-risk drinkers, men had higher AUDIT scores, $t(568)=2.9, p=0.003$.

\section{Go/No-Go Task}

Valid go/no-go data were obtained for 679 participants (22 participants were missing data and 42 participants had invalid data). Figure 3 presents mean inhibitory failures separately for men and women in the at-risk and non-risk drinker groups. The figure shows that overall women committed more inhibitory failures than men, as evidenced by a main effect of sex, $F(1$, $675)=6.53, p=0.011$. Moreover, the figure shows that the sex difference was more pronounced in the at-risk drinker group compared to the non-risk group. This was confirmed by a significant sex $\times$ group interaction, $F(1,675)=3.88, p=0.049$. Followup between-groups $t$-tests showed significantly more inhibitory failures in women than men in the at-risk group, $t(152)=2.58$, $p=0.011$, but no difference in women and men in the nonrisk group, $t(523)=0.60, p=0.55$. No significant differences were observed between risk groups among men or women $(t \mathrm{~s}<1.85$, ps $>0.05)$.

\section{Delay Discounting Task}

Valid delay discounting data were obtained for 734 participants (6 participants were missing data and 3 participants had invalid data). Figure 4 presents mean AUC of the discounting curve separately for men and women in the at-risk and non-risk drinker groups. Neither men and women nor risk groups differed on this measure $(p s>0.40)$.

\section{Associations Between Task Performance and Demographics}

Performance on the go/no-go task was not related to delay discounting in the sample as a whole $(r=0.01, p=0.73)$ or when

TABLE 1 | Demographics and drug use characteristics of participants

\begin{tabular}{|c|c|c|c|c|c|c|}
\hline & \multicolumn{3}{|c|}{ At-risk drinkers } & \multicolumn{3}{|c|}{ Non-risk drinkers } \\
\hline & Men $(n=90)$ & Women $(n=83)$ & Total $(n=173)$ & Men $(n=206)$ & Women $(n=364)$ & Total $(n=570)$ \\
\hline Age (mean, SD) & $23.3(3.5)$ & $22.0(2.8)$ & $22.6(3.2)$ & $23.3(3.3)$ & $22.9(3.1)$ & $23.0(3.2)$ \\
\hline Education in years (mean, SD) & $15.3(2.3)$ & $14.9(1.9)$ & $15.1(2.1)$ & $15.4(2.3)$ & $15.5(2.0)$ & $15.5(2.1)$ \\
\hline \multicolumn{7}{|l|}{ Race (number, \%) } \\
\hline Caucasian & 80 (89\%) & 79 (95\%) & $159(92 \%)$ & 187 (91\%) & 329 (90\%) & $516(91 \%)$ \\
\hline African-American & $2(2 \%)$ & & $2(1 \%)$ & $11(5 \%)$ & $14(4 \%)$ & $25(4 \%)$ \\
\hline Asian & 7 (8\%) & & $7(4 \%)$ & $5(2 \%)$ & $15(4 \%)$ & $20(4 \%)$ \\
\hline Other & $1(1 \%)$ & $4(5 \%)$ & $5(3 \%)$ & $3(2 \%)$ & $6(2 \%)$ & $9(1 \%)$ \\
\hline IQ (mean, SD) & $119.0(10.5)$ & $120.3(10.3)$ & $119.6(10.4)$ & $119.5(9.4)$ & $118.7(9.2)$ & $119.0(9.3)$ \\
\hline \multicolumn{7}{|l|}{ Alcohol use measures } \\
\hline AUDIT (mean, SD) & $10.5(2.5)$ & $10.2(2.4)$ & $10.3(2.4)$ & $4.5(1.7)$ & $4.1(1.9)$ & $4.2(1.8)$ \\
\hline \multicolumn{7}{|l|}{ TLFB $^{\mathrm{a}}$ (mean, SD) } \\
\hline Drinking days/month & $13.0(6.5)$ & $11.0(5.8)$ & $12.2(6.2)$ & $8.2(6.0)$ & $7.4(5.4)$ & $7.7(5.6)$ \\
\hline Binges/month & $4.5(3.5)$ & $4.4(3.6)$ & $4.5(3.5)$ & $1.2(1.7)$ & $1.3(1.8)$ & $1.3(1.7)$ \\
\hline Cigarettes/day (mean/SD) & $1.1(2.6)$ & $0.6(1.3)$ & $0.9(2.1)$ & $0.6(1.8)$ & $0.5(2.2)$ & $0.5(2.1)$ \\
\hline \multicolumn{7}{|l|}{ Marijuana (number, \%) } \\
\hline None & $31(34 \%)$ & 34 (41\%) & 65 (37\%) & 125 (61\%) & 245 (67\%) & $370(65 \%)$ \\
\hline Monthly & $37(41 \%)$ & $37(45 \%)$ & $74(43 \%)$ & $52(25 \%)$ & $94(26 \%)$ & $146(26 \%)$ \\
\hline Weekly & $17(19 \%)$ & $10(12 \%)$ & $27(16 \%)$ & $22(11 \%)$ & $24(6.5 \%)$ & $46(8 \%)$ \\
\hline Daily & $5(6 \%)$ & $2(2 \%)$ & 7 (4\%) & 7 (3\%) & $1(0.5 \%)$ & $8(1 \%)$ \\
\hline
\end{tabular}

${ }^{a}$ Data gathered from a subset of participants $(n=457)$. 


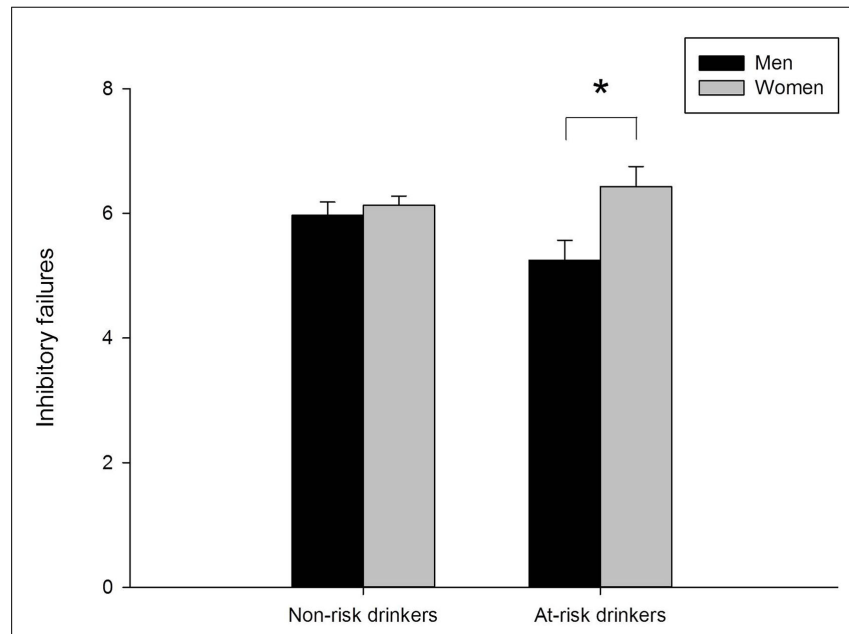

FIGURE 3 | Mean inhibitory failures on the go/no-go task for men and women in the non-risk (AUDIT scores below 8) and at-risk (AUDIT scores of $\mathbf{8}$ or above) drinker groups. In the non-risk group, men $(n=190)$ and women $(n=335)$ did not differ. In the at-risk group, women $(n=75)$ committed significantly more inhibitory failures than men $(n=79), p=0.01$. Capped vertical lines represent standard error of the mean (SEM).

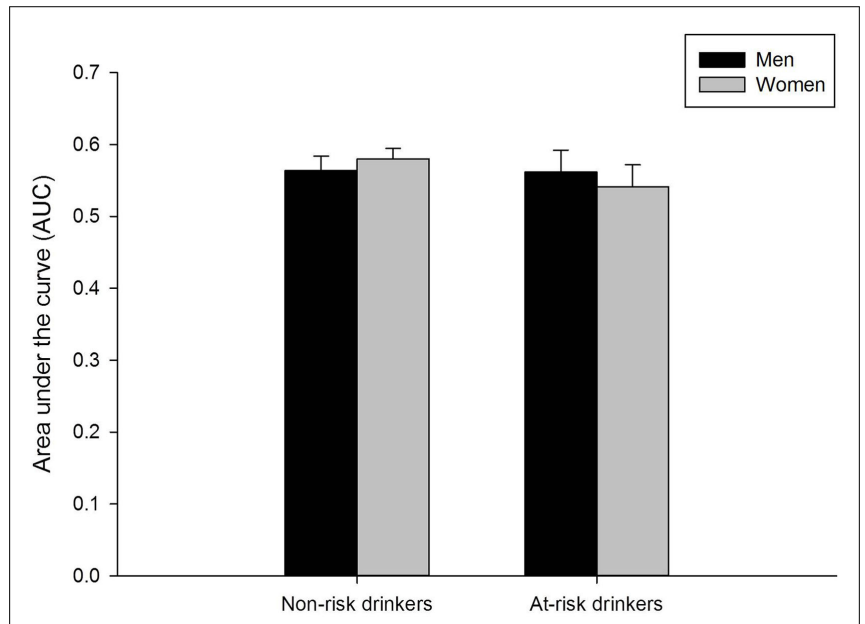

FIGURE 4 | Mean area under the curve on the delay discounting task for men and women in the non-risk (AUDIT scores below 8) and at-risk (AUDIT scores of $\mathbf{8}$ or above) drinker groups. No sex differences were observed in either group. Capped vertical lines represent standard error of the mean (SEM).

analyzed individually by sex (men: $r=-0.01, p=0.84$; women: $r=0.03, p=0.54)$. Inhibitory failures on the go/no-go task were negatively correlated with age $(r=-0.20, p<0.001)$ and education $(r=-0.08, p=0.04)$. AUC of the discounting curve was positively correlated with education $(r=0.12, p=0.001)$ and IQ $(r=0.22, p<0.001)$. As greater AUC indicates less discounting, these correlations indicate that greater impulsive choice is associated with lower IQ and less education. Sex differences in both go/no-go task performance and delay discounting were reanalyzed controlling for each of these demographic variables, and the results remained unchanged.

\section{Discussion}

This study examined sex differences in behavioral impulsivity (i.e., poor inhibitory control and impulsive choice) in at-risk and non-risk drinkers. Risk status was determined by scores on the AUDIT, a self-report measure that assesses frequency and quantity of alcohol consumption and alcohol-related problems. As hypothesized, at-risk women displayed poorer inhibitory control than at-risk men, but no sex differences were observed in the nonrisk drinkers. On impulsive choice, no differences were observed in either men vs. women or by risk group.

Our findings of sex differences in inhibitory control are largely consistent with previous reports. Specifically, other studies have shown that heavy drinking women exhibit greater inhibitory deficits than heavy drinking men and light drinkers $(30,31)$. Further, in previous studies of women only, heavy drinking women show greater inhibitory deficits than light drinking women $(40,41)$. Although statistically significant differences were not observed between the at-risk and non-risk women in the current study, the direction of findings are in line with these reports and provide further support for inhibitory deficits among hazardous female drinkers. Regarding impulsive choice, the current findings are not consistent with one prior report of greater discounting among men compared to women in a sample of both alcoholdependent individuals and controls (32). As no participants met dependence criteria in the current study, it could be that sex differences in delay discounting are more pronounced among individuals with alcohol use disorders. Taken together, these findings suggest that problematic alcohol consumption in women is strongly linked to poor inhibitory control, but not delay discounting.

Given mounting evidence of a link between disinhibition and heavy drinking in women, it is important to determine the causal direction of this association, as inhibitory deficits could be either a cause or consequence, or both, of heavy drinking. Evidence that sex-specific biological factors contribute to poor inhibition in non-alcohol abusing women would suggest that inhibitory deficits precede the onset of heavy drinking. For example, sex differences in circulating levels of gonadal hormones, including estradiol (E2), could influence inhibitory control. Indeed, Colzato et al. (20) showed that women exhibit poorer inhibition than men only when E2 levels are high, and that poorer inhibition is correlated with higher salivary measures of E2. Additionally, sex differences could exist in activation of neural circuitry underlying inhibitory control. Initial neuroimaging studies have reported that this circuitry is less strongly activated during response inhibition in women compared to men (42-45), although there are also reports of less activation in men (46), or complex differential patterns of activation in men and women (47). In sum, there is preliminary evidence of biologically based mechanisms underlying sex differences in inhibitory control, suggesting that poor inhibition may precede, and be a risk factor for, excessive and problematic alcohol use in women.

Alternately, evidence that women are more sensitive to the neurotoxic effects of alcohol would suggest that observed inhibitory deficits in women are a consequence of heavy drinking. Although findings are mixed, there is some evidence of greater adverse effects of alcohol on brain structure in adult female compared 
to male alcoholics [for review, see Ref. (48)]. Further, in a sample of adolescents, Squeglia et al. (49) observed thicker cortices (indicative of less synaptic pruning) in frontal regions in binge drinking females compared to controls, as well as an association between thicker cortices and poorer inhibition in females. This group also observed decreased brain activation in female binge drinkers compared to controls during performance of a spatial working memory task, and decreased activation was associated with poorer task performance (50). Although no studies to date have examined neural activation underlying poor inhibitory control in heavy drinking female adolescents or adults, there is evidence to suggest that females may be more sensitive to the adverse effects of alcohol on inhibition-related brain structure and function.

There are several limitations to this study. First, we did not specifically recruit for heavy drinkers and excluded any potential volunteers with a history of alcohol dependence. As such, non-risk drinkers were over-represented in this sample, and this may have contributed in part to our failure to replicate wellestablished findings showing greater impulsive behavior in hazardous drinkers. Indeed, meta-analyses of impulsive behavior (poor inhibitory control and greater impulsive choice) report the most pronounced effects when alcohol dependent individuals are compared to healthy controls, and much weaker effects for non-dependent drinkers compared to controls $(13,17)$. It will be important for future studies to examine sex difference in impulsive behaviors within alcohol dependent populations, while taking into account other psychiatric symptoms that could influence sex differences, such as anhedonia (51). An additional limitation of the sample is the over-representation of women. It is important to

\section{References}

1. Keyes KM, Grant BF, Hasin DS. Evidence for a closing gender gap in alcohol use, abuse, and dependence in the United States population. Drug Alcohol Depend (2008) 93:21-9. doi:10.1016/j.drugalcdep.2007.08.017

2. Balodis IM, Potenza MN, Olmstead MC. Binge drinking in undergraduates: relationships with sex, drinking behaviors, impulsivity, and the perceived effects of alcohol. Behav Pharmacol (2009) 20:518-26. doi:10.1097/FBP. 0b013e328330c779

3. Keyes KM, Martins SS, Blanco C, Hasin DS. Telescoping and gender differences in alcohol dependence: new evidence from two national surveys. Am J Psychiatry (2010) 167:969-76. doi:10.1176/appi.ajp.2009.09081161

4. Substance Abuse and Mental Health Services Administration (SAMHSA). Results from the 2012 National Survey on Drug Use and Health: Summary of National Findings. (2012). Available from: http://media.samhsa. gov/data/NSDUH/2012SummNatFindDetTables/NationalFindings/ NSDUHresults2012.htm\#ch3.2

5. Twigg L, Moon G. The spatial and temporal development of binge drinking in England 2001-2009: an observational study. Soc Sci Med (2013) 91:162-7. doi:10.1016/j.socscimed.2013.03.023

6. Brady KT, Randall CL. Gender differences in substance use disorders. Psychiatr Clin North Am (1999) 22:241-52. doi:10.1016/S0193-953X(05)70074-5

7. Becker JB, Hu M. Sex differences in drug abuse. Front Neuroendocrinol (2008) 29:36-47. doi:10.1016/j.yfrne.2007.07.003

8. Anker JJ, Carroll ME. Females are more vulnerable to drug abuse than males: evidence from preclinical studies and the role of ovarian hormones. Curr Top Behav Neurosci (2010) 8:73-96. doi:10.1007/7854_2010_93

9. Perry JL, Carroll ME. The role of impulsive behavior in drug abuse. Psychopharmacology (2008) 200:1-26. doi:10.1007/s00213-008-1173-0

10. de Wit H. Impulsivity as a determinant and consequence of drug use: a review of underlying processes. Addict Biol (2009) 14:22-31. doi:10.1111/j.1369-1600. 2008.00129.x note, however, that numbers of men and women were balanced within the at-risk drinker group. A third limitation is the lack of assessment of sex hormones. Circulating levels of gonadal hormones influence both inhibitory control (20) and impulsive choice $(29,52)$, and it is crucial that future studies examining sex differences in impulsive behavior account for the role of hormones in any observed differences.

In sum, this study adds to the existing literature suggesting that poor inhibitory control is strongly linked to problematic alcohol consumption in women. Future longitudinal research is needed to determine whether poor inhibitory control is a cause, or consequence, or both of heavy drinking in women. A better understanding of this association will allow for the development of sex-specific prevention and treatment efforts for alcohol abuse, with a focus on the role of poor inhibitory control.

\section{Author Contributions}

JW and JDA oversaw data acquisition and management, conducted the data analyses, and conducted the literature review and co-wrote the first draft of the paper. JW, JDA, and HdW contributed to and approved the final version of the paper.

\section{Acknowledgments}

This research was supported by National Institute on Drug Abuse Grants DA032015 and DA002812 (HdW) and F32 DA033756 (JW). NIDA had no involvement other than financial support. We would like to thank James MacKillop, Ph.D., and Joshua Gray, MS for assistance with processing of the delay discounting data.

11. Weafer J, Mitchell SH, de Wit H. Recent translational findings on impulsivity in relation to drug abuse. Curr Addict Rep (2015) 1:289-300. doi:10.1007/ s40429-014-0035-6

12. Lawrence AJ, Luty J, Bogdan NA, Sahakian BJ, Clark L. Impulsivity and response inhibition in alcohol dependence and problem gambling. Psychopharmacology (2009) 207:163-72. doi:10.1007/s00213-009-1645-x

13. Smith JL, Mattick RP, Jamadar SD, Iredale JM. Deficits in behavioural inhibition in substance abuse and addiction: a meta-analysis. Drug Alcohol Depend (2014) 145:1-33. doi:10.1016/j.drugalcdep.2014.08.009

14. Nigg JT, Wong MM, Martel MM, Jester JM, Puttler LI, Glass JM, et al. Poor response inhibition as a predictor of problem drinking and illicit drug use in adolescents at risk for alcoholism and other substance use disorders. J Am Acad Child Adolesc Psychiatry (2006) 45:468-75. doi:10.1097/01.chi.0000199028. 76452.a9

15. Rubio G, Jimenez M, Rodriguez-Jimenez R, Martinez I, Avila C, Ferre F, et al. The role of behavioral impulsivity in the development of alcohol dependence: a 4-year follow-up study. Alcohol Clin Exp Res (2008) 32:1681-7. doi:10.1111/j. 1530-0277.2008.00746.x

16. Fernie G, Peeters M, Gullo MJ, Christiansen P, Cole JC, Sumnall H, et al. Multiple behavioural impulsivity tasks predict prospective alcohol involvement in adolescents. Addiction (2013) 108:1916-23. doi:10.1111/add.12283

17. MacKillop J, Amlung MT, Few LR, Ray LA, Sweet LH, Munafo MR. Delayed reward discounting and addictive behavior: a meta-analysis. Psychopharmacology (Berl) (2011) 216:305-21. doi:10.1007/s00213-011-2229-0

18. Courtney KE, Arellano R, Barkley-Levenson E, Galvan A, Poldrack RA, Mackillop J, et al. The relationship between measures of impulsivity and alcohol misuse: an integrative structural equation modeling approach. Alcohol Clin Exp Res (2012) 36:923-31. doi:10.1111/j.1530-0277.2011.01635.x

19. Weafer J, de Wit H. Sex differences in impulsive action and impulsive choice. Addict Behav (2014) 39:1573-9. doi:10.1016/j.addbeh.2013.10.033

20. Colzato LS, Hertsig G, Van Den Wildenberg WP, Hommel B. Estrogen modulates inhibitory control in healthy human females: evidence from the stop-signal 
paradigm. Neuroscience (2010) 167:709-15. doi:10.1016/j.neuroscience.2010. 02.029

21. Morgan JE, Gray NS, Snowden RJ. The relationship between psychopathy and impulsivity: a multi-impulsivity measurement approach. Pers Individ Dif (2011) 51:429-34. doi:10.1016/j.paid.2011.03.043

22. Saunders B, Farag N, Vincent AS, Collins FL Jr, Sorocco KH, Lovallo WR. Impulsive errors on a Go-NoGo reaction time task: disinhibitory traits in relation to a family history of alcoholism. Alcohol Clin Exp Res (2008) 32:888-94. doi:10.1111/j.1530-0277.2008.00648.x

23. Hasson RF, Fine JG. Gender differences among children with ADHD on continuous performance tests: a meta-analytic review. J Atten Disord (2012) 16:190-8. doi:10.1177/1087054711427398

24. Liu T, Xiao T, Shi J. Response inhibition, preattentive processing, and sex difference in young children: an event-related potential study. Neuroreport (2013) 24:126-30. doi:10.1097/WNR.0b013e32835d846b

25. Reynolds B, Ortengren A, Richards JB, de Wit H. Dimensions of impulsive behavior: personality and behavioral measures. Pers Individ Dif (2006) 40:305-15. doi:10.1016/j.paid.2005.03.024

26. Smith CL, Hantula DA. Methodological considerations in the study of delay discounting in intertemporal choice: a comparison of tasks and modes. Behav Res Methods (2008) 40:940-53. doi:10.3758/BRM.40.4.940

27. Beck RC, Triplett MF. Test-retest reliability of a group-administered paperpencil measure of delay discounting. Exp Clin Psychopharmacol (2009) 17:345-55. doi:10.1037/a0017078

28. Kirby K, Marakovic NN. Delay-discounting probabilistic rewards: rates decrease as amounts increase. Psychon Bull Rev (1996) 3:100-4. doi:10.3758/ BF03210748

29. Doi H, Nishitani S, Shinohara K. Sex difference in the relationship between salivary testosterone and inter-temporal choice. Horm Behav (2015) 69:50-8. doi:10.1016/j.yhbeh.2014.12.005

30. Townshend JM, Duka T. Binge drinking, cognitive performance and mood in a population of young social drinkers. Alcohol Clin Exp Res (2005) 29:317-25. doi:10.1097/01.ALC.0000156453.05028.F5

31. Nederkoorn C, Baltus M, Guerrieri R, Wiers RW. Heavy drinking is associated with deficient response inhibition in women but not in men. Pharmacol Biochem Behav (2009) 93:331-6. doi:10.1016/j.pbb.2009.04.015

32. Bobova L, Finn PR, Rickert ME, Lucas J. Disinhibitory psychopathology and delay discounting in alcohol dependence: personality and cognitive correlates. Exp Clin Psychopharmacol (2009) 17:51-61. doi:10.1037/a0014503

33. Yankelevitz RL, Mitchell SH, Zhang Y. Gender differences in factors associated with alcohol drinking: delay discounting and perception of others' drinking. Drug Alcohol Depend (2012) 123:273-6. doi:10.1016/j.drugalcdep. 2011.11.012

34. Babor TF, Kranzler HR, Lauerman RJ. Early detection of harmful alcohol consumption: comparison of clinical, laboratory, and self-report screening procedures. Addict Behav (1989) 14:139-57. doi:10.1016/0306-4603(89)90043-9

35. American Psychiatric Association. Diagnostic and Statistical Manual of Mental Disorders. Washington, DC: American Psychiatric Association (1994).

36. Fillmore MT, Weafer J. Behavioral inhibition and addiction. In: MacKillop J, de Wit H, editors. The Wiley-Blackwell Handbook of Addiction Psychopharmacology. West Sussex: John Wiley and Sons Limited (2013). p. 135-64.

37. Richards JB, Zhang L, Mitchell SH, de Wit H. Delay or probability discounting in a model of impulsive behavior: effect of alcohol. J Exp Anal Behav (1999) 71:121-43. doi:10.1901/jeab.1999.71-121

38. Ohmura Y, Takahashi T, Kitamura N, Wehr P. Three-month stability of delay and probability discounting measures. Exp Clin Psychopharmacol (2006) 14:318-28. doi:10.1037/1064-1297.14.3.318
39. Sobell LC, Sobell MB. Timeline follow-back: a technique for assessing selfreported alcohol consumption. In: Litten RZ, Allen JP, editors. Measuring Alcohol Consumption: Psychosocial and Biochemical Methods. Totowa, NJ: Humana Press (1992). p. 41-72.

40. Reed SC, Levin FR, Evans SM. Alcohol increases impulsivity and abuse liability in heavy drinking women. Exp Clin Psychopharmacol (2012) 20:454-65. doi:10. 1037/a0029087

41. Smith JL, Mattick RP. Evidence of deficits in behavioural inhibition and performance monitoring in young female heavy drinkers. Drug Alcohol Depend (2013) 133:398-404. doi:10.1016/j.drugalcdep.2013.06.020

42. Li CS, Huang C, Constable RT, Sinha R. Gender differences in the neural correlates of response inhibition during a stop signal task. Neuroimage (2006) 32:1918-29. doi:10.1016/j.neuroimage.2006.05.017

43. Li CS, Zhang S, Duann JR, Yan P, Sinha R, Mazure CM. Gender differences in cognitive control: an extended investigation of the stop signal task. Brain Imaging Behav (2009) 3:262-76. doi:10.1007/s11682-009-9068-1

44. Liu J, Zubieta JK, Heitzeg M. Sex differences in anterior cingulate cortex activation during impulse inhibition and behavioral correlates. Psychiatry Res (2012) 201:54-62. doi:10.1016/j.pscychresns.2011.05.008

45. DeVito EE, Meda SA, Jiantonio R, Potenza MN, Krystal JH, Pearlson GD. Neural correlates of impulsivity in healthy males and females with family histories of alcoholism. Neuropsychopharmacology (2013) 38:1854-63. doi:10.1038/npp. 2013.92

46. Garavan H, Hester R, Murphy K, Fassbender C, Kelly C. Individual differences in the functional neuroanatomy of inhibitory control. Brain Res (2006) 1105:130-42. doi:10.1016/j.brainres.2006.03.029

47. Rubia K, Lim L, Ecker C, Halari R, Giampietro V, Simmons A, et al. Effects of age and gender on neural networks of motor response inhibition: from adolescence to mid-adulthood. Neuroimage (2013) 83:690-703. doi:10.1016/j.neuroimage. 2013.06.078

48. Sharrett-Field L, Butler TR, Reynolds AR, Berry JN, Prendergast MA. Sex differences in neuroadaptation to alcohol and withdrawal neurotoxicity. Pflugers Arch (2013) 465:643-54. doi:10.1007/s00424-013-1266-4

49. Squeglia LM, Sorg SF, Schweinsburg AD, Wetherill RR, Pulido C, Tapert SF. Binge drinking differentially affects adolescent male and female brain morphometry. Psychopharmacology (Berl) (2012) 220:529-39. doi:10.1007/ s00213-011-2500-4

50. Squeglia LM, Schweinsburg AD, Pulido C, Tapert SF. Adolescent binge drinking linked to abnormal spatial working memory brain activation: differential gender effects. Alcohol Clin Exp Res (2011) 35:1831-41. doi:10.1111/j.1530-0277. 2011.01527.x

51. Hatzigiakoumis DS, Martinotti G, Di Giannantonio M. Anhedonia and substance dependence: clinical correlates and treatment options. Front Psychiatry (2011) 2:10. doi:10.3389/fpsyt.2011.00010

52. Smith CT, Sierra Y, Oppler SH, Boettiger CA. Ovarian cycle effects on immediate reward selection bias in humans: a role for estradiol. J Neurosci (2014) 34:5468-76. doi:10.1523/JNEUROSCI.0014-14.2014

Conflict of Interest Statement: The authors declare that the research was conducted in the absence of any commercial or financial relationships that could be construed as a potential conflict of interest.

Copyright $(\odot 2015$ Weafer, De Arcangelis and de Wit. This is an open-access article distributed under the terms of the Creative Commons Attribution License (CC BY). The use, distribution or reproduction in other forums is permitted, provided the original author(s) or licensor are credited and that the original publication in this journal is cited, in accordance with accepted academic practice. No use, distribution or reproduction is permitted which does not comply with these terms. 